\title{
Avaliação agronômica de novos clones de Manihot esculenta Crantz no segundo ciclo vegetativo
}

\author{
Rodrigo Magno de SOUSA ${ }^{1 *}$, Mateus Alves de SOUSA ${ }^{1}$, Renata Soares dos SANTOS ${ }^{1}$, \\ Edwin Camacho PALOMINO ${ }^{1}$ \\ ${ }^{1}$ Universidade Federal do Oeste do Pará, Santarém, PA, Brasil. \\ *E-mail: rodrigosousabranches@gmail.com \\ (Orcid: 0000-0001-9312-6347; 0000-0002-9696-743X; 0000-0003-4370-7090; 0000-0001-7331-0999)
}

\begin{abstract}
Recebido em 30/07/2020; Aceito em 12/07/2021; Publicado em 14/07/2021.
RESUMO: O presente trabalho teve como objetivo avaliar as características agronômicas no segundo ciclo vegetativo de novos clones de mandioca de mesa oriundos de um programa de melhoramento, nas condições edafoclimáticas do município de Santarém, Oeste do Pará. O delineamento experimental utilizado foi em blocos casualizados com 13 tratamentos (novos clones de macaxeira) e três repetições. As parcelas foram constituídas por 10 plantas distribuídas em duas linhas de 5 metros, com espaçamento de 1,0 x 1,0 m. Os resultados obtidos denotam que a produtividade apresentou correlação significativa e positiva com a massa de raízes comerciais $(\mathrm{r}=0,98)$, massa fresca da parte aérea $(\mathrm{r}=0,61)$ e diâmetro médio das raízes $(\mathrm{r}=0,63)$, com destaque para $\mathrm{o}$ clone C5 que obteve maiores rendimentos em relação a estas características, e consequentemente apresentou maior média de produtividade $44,70 \mathrm{t} \mathrm{ha}^{-1}$. Em relação ao tempo de cozimento das raízes, de treze clones testados, doze materiais obtiveram tempo médio de cozimento inferior a trinta minutos, sendo classificados como tempo de cozimento bom, com destaque para o clone C11, que apresentou média de 12,30 minutos. Todos os clones avaliados apresentam características agronômicas desejáveis tornando-se promissores para o mercado do município de Santarém, no baixo Amazonas.

Palavras-chave: melhoramento; baixo amazonas; produtividade; mandioca de mesa.

\section{Agronomic evaluation of new Manihot esculenta Crantz clones in the second vegetative cycle}

\begin{abstract}
The present work aimed to evaluate the agronomic characteristics in the second vegetative cycle of new macaxeira clones from a breeding program under the edaphoclimatic conditions of the municipality of Santarém, Western Pará. The experimental design was randomized blocks with 13 treatments (new clones of cassava) and three repetitions. The plots consisted of 10 plants distributed in two rows of 5 meters, with $1.0 \mathrm{x}$ $1.0 \mathrm{~m}$ spacing. The results show that yield was significantly and positively correlated with commercial root mass $(\mathrm{r}=0.98)$, fresh shoot mass $(\mathrm{r}=0.61)$ and mean root diameter $(\mathrm{r}=0.63)$. highlighting clone C5 that obtained higher yields in relation to these characteristics, and consequently presented higher average yield 44.70 t ha- 1 . Regarding the root cooking time, of thirteen clones tested, twelve materials had an average cooking time of less than thirty minutes, being classified as good cooking time, especially clone C11, which presented an average of 12.30 minutes. All evaluated clones have desirable agronomic characteristics making them promising for the lower Amazon market.
\end{abstract}

Keywords: breeding; low amazons; productivity; table cassava.

\section{INTRODUÇÃO}

A mandioca (Manihot esculenta Crantz), também conhecida em diversas regiões como mandioca de mesa, aipim ou macaxeira, é caracterizada como uma planta perene do tipo arbustiva pertencente à família Euphorbiaceae (LARA et al., 2008). Originária na américa do sul, a mandioca é cultivada em todo território nacional principalmente por pequenos produtores, que a utiliza em

sua maioria como fonte de subsistência. Considerada a quarta cultura de produção de alimentos mais importante do mundo, a cultura apresenta grande importância socioeconômica principalmente em região tropicais, pois sua raiz e demais subprodutos são consumidos por cerca de 800 milhões de pessoas (FAO, 2013).

A cultura possui uma gama de variedades adaptadas a diferentes condições edafoclimáticas, estas são diferenciadas principalmente por características morfológicas como cor do pecíolo, forma e textura da raiz, forma e cor das folhas, além da concentração de ácido cianídrico nas raízes. Os programas de melhoramento, conduzidos por instituições de pesquisas, são os principais responsáveis pela seleção de variedades altamente produtivas e que apresentam ciclo precoce e tolerância a pragas e doenças.

O principal produto da cultura da mandioca são as raízes, entretanto a parte aérea também é utilizada, na alimentação animal. Para Borém (2005), a produtividade ou rendimento de raízes está correlacionada com outros caracteres da planta, os quais compõem a produção, são eles, o peso de raízes, massa fresca da parte aérea, número de raízes por planta, 
altura da planta e o índice de colheita. De acordo com Fukuda (2002), os objetivos nos programas de melhoramento da mandioca são definidos pela cadeia produtiva, demanda de produção e mercado, sendo esses mecanismos específicos para cada localidade, no entanto, o aumento da produtividade de raízes e resistência a doenças e pragas são objetivos comuns em todas as regiões.

A mandioca é uma espécie alógama que apresenta alta heterozigose e ampla segregação na primeira geração após a hibridação, ao se identificar um genótipo superior nessa geração, se inicia o processo de propagação vegetativa ou clonagem do híbrido (LARA et al., 2008). Apesar dessa grande vantagem no trabalho de melhoramento da mandioca, o grande número de populações que são avaliadas nos estudos, dificulta as análises com precisão dos genótipos superiores gerados, além da pouca quantidade de manivas por planta e o ciclo longo, que acabam dificultando o trabalho do melhorista.

As características de interesse agronômico para mandioca, em geral, são controladas por diversos genes com efeitos aditivos, por serem complexos, estes necessitam de longos períodos para se fixar em um genótipo (BORÉM, 2005). Apesar da cultura da mandioca apresentar adaptação a diferentes condições edafoclimáticas, os genótipos dispõem de alta interação com o ambiente, o que indica que os genótipos iguais dificilmente se comportam de maneira semelhante em ambientes diferentes, tal fato explica-se por múltiplos fatores entre eles pela alta incidência de pragas e doenças que afetam a espécie, cuja gravidade é limitada pelas condições ambientais (LARA et al., 2008).

Para Vieira (2013) os caracteres fenotípicos quantitativos apresentam maior influência ambiental pelo fato de serem governados por vários genes, porém, essa ferramenta auxilia na caracterização de acessos, uma vez que refletirá seu real potencial produtivo, possibilitando a utilização deles de forma direta ou indireta no melhoramento genético, por sua vez, os descritores qualitativos apresentam baixa ou nenhuma influência do ambiente, além de fácil mensuração, os mesmos apresentam menor custo.

Segundo Gonçalves et al. (2008) a compreensão sobre a correlação entre características fenotípicas é importante para a consecução de um programa de melhoramento bem planejado, as associações são levadas em consideração na escolha dos métodos de melhoramento quando elaboram estratégias de seleção simultânea para as diversas variáveis analisadas. Sendo assim, o conhecimento sobre as características moleculares, morfológicas e fisiológicas da cultura, fornecem informações que permitem a condução do cruzamento, seleção e obtenção de genótipos promissores.

Os sistemas de cultivo da mandioca no Brasil ocorrem com baixo nível tecnológico, as variedades utilizadas geralmente não passaram por um processo formal de melhoramento genético, o que acarreta baixa produtividade, pois estas apresentam em sua maioria susceptibilidade a insetos-pragas e doenças, além de não dispor potencial genético para produção de raízes tuberosas (VIEIRA et al., 2015).

O cultivo comercial da mandioca ocorre em mais de 80 países, sendo que $15 \%$ da produção mundial é cultivada no Brasil (MODESTO JUNIOR; ALVES, 2016). A região norte apresenta-se como a maior produtora de mandioca do país, destacando-se o estado do Pará com $70 \%$ da produção total da região (SEDAP, 2018). Um dos fatores que contribui para tal fato é que o Estado abrange maior área plantada de mandioca no Brasil com 20,97\% do total, cerca de 295.137 ha. A produtividade média de raízes por unidade de área no país é de 14,64 t ha-1, o estado do Pará por sua vez produz em média 14,34 t ha ${ }^{-1}$, e o município de Santarém-PA apresenta cerca de $10 \mathrm{t} \mathrm{ha}^{-1}$ (EMBRAPA, 2017).

A estimativa de produção nacional de raízes de mandioca para o período de março/2019 foi de 20,5 milhões de toneladas, cultivadas numa área de 1,6 milhões de ha, crescimento de $1,6 \%$ em relação ao mês anterior (CONAB, 2019). A produção de mandioca em março/2018 foi de 19,39 milhões de toneladas de raízes e a produtividade de 14,18 t $\mathrm{ha}^{-1}$, levantamentos apontaram que durante o mesmo período em 2019 a produtividade teria um ganho de 4,99\%, e a produção 5,6\% maior que o ano anterior (IBGE, 2019).

Nesse sentido, o presente trabalho teve como objetivo avaliar as características agronômicas, no segundo ciclo vegetativo, de novos clones de macaxeira em condições edafoclimáticas do município de Santarém, Oeste do Pará.

\section{MATERIAL E MÉTODOS}

O estudo foi conduzido em área de produtor rural localizada na comunidade São José, sob as coordenadas geográficas $2^{\circ} 24^{\prime} 52^{\prime \prime} \mathrm{S}$ e $54^{\circ} 42^{\prime} 36^{\prime \prime W}$, no município de Santarém, Oeste do Pará. O clima predominante na região é quente e úmido com temperatura média anual variando entre $25^{\circ}$ a $28^{\circ} \mathrm{C}$. A umidade relativa média do ar é de $86 \%$, a precipitação pluvial média anual é de $1920 \mathrm{~mm}$ (INMET, 2018). O ensaio foi conduzido entre o período de maio de 2018 a maio de 2019 e o regime pluviométrico apresentado na figura 1.

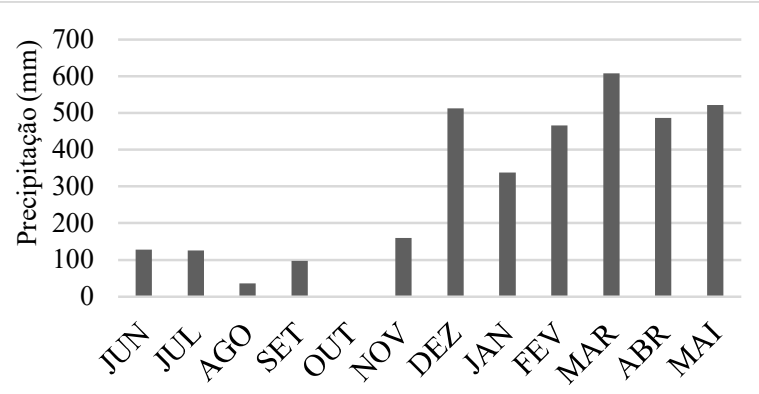

Figura 1. Médias mensais de precipitação durante o período de junho de 2018 a maio de 2019 no município de Santarém-PA. Fonte: INMET - Instituto Nacional de Meteorologia.

Figure 1. Monthly monitoring averages during the period from June 2018 to May 2019 in the municipality of Santarém-PA. Source: INMET - National Institute of Meteorology.

\subsection{Preparo de área experimental}

$\mathrm{O}$ experimento foi conduzido em área com predominância de solo do tipo Latossolo amarelo distrófico. O plantio foi realizado após a limpeza de área (roçagem), posteriormente ocorreu a abertura de covas nas dimensões de $20 \mathrm{~cm}$ largura e $10 \mathrm{~cm}$ de profundidade, em um espaçamento de 1,0 m entre plantas e entre linhas.

\subsection{Material vegetal utilizado}

Foram utilizados treze clones de macaxeira oriundos do primeiro teste clonal instalado na comunidade de Boa Esperança, no município de Santarém-PA. No mês de maio de 2018 foram coletadas as ramas (material propagativo) a partir do terço médio do caule de cada clone selecionado, estes foram organizados em feixes, identificados e 
armazenados durante quatorze dias em ambiente sombreado com as hastes dispostas verticalmente, e um dia antes do plantio procedeu-se a confecção das maniva-sementes com aproximadamente $20 \mathrm{~cm}$ de comprimento, apresentando em média 10 gemas por maniva.

\subsection{Delineamento experimental}

O delineamento experimental utilizado foi em blocos casualizados (DBC) com 13 tratamentos (novos clones de mandioca de mesa) e três repetições. As parcelas foram constituídas por 10 plantas distribuídas em duas linhas de 5 metros, com espaçamento de 1,0 x 1,0 m entre plantas e entre linhas, obtendo uma densidade populacional de 10.000 plantas ha-1.

\subsection{Caracteres agronômicos avaliados}

Foram avaliados 12 características quantitativas doze meses após o plantio, sendo: altura de plantas em metros $(\mathrm{H})$, diâmetro do caule em milímetros (D), produtividade em tha$1(\mathrm{P})$, massa da raiz comercial e não comercial em t ha ${ }^{-1}$ (MRC e MRNC), massa fresca da parte aérea em $\mathrm{kg}$ planta $^{-1}$ (MFPA), número de raiz comercial e não comercial (NRC e NRNC), comprimento de raízes em $\mathrm{cm}$ (CR), diâmetro de raízes em $\mathrm{mm}$ (DR), tempo médio de cozimento de raízes em minutos (TC) e índice de colheita (IC). Estes foram obtidos da seguinte forma:

a) Altura de plantas: A altura de plantas foi realizada com o uso de uma régua graduada, onde efetuou-se a medida partir da superfície do solo até a copa da planta.

b) Diâmetro do caule: Para determinação do diâmetro do caule, utilizou-se um paquímetro digital graduado em milímetros, onde foi medido a $20 \mathrm{~cm}$ acima da superfície do solo.

c) Produtividade de raízes: Durante o processo de colheita efetuou-se a pesagem de todas as raízes tuberosas produzidas pelas plantas constituintes da área útil nas parcelas experimentais. Os dados foram mensurados e extrapolados para $t \mathrm{ha}^{-1}$.

d) Massa de raízes comerciais: Obtido a partir da pesagem apenas das raízes tuberosas da parcela útil que atenderam os critérios comerciais, ou seja, características subjetivas como maior comprimento, diâmetro e qualidade visual atrativa (cor da raiz), os dados foram extrapolados para $t \mathrm{ha}^{-1}$.

e) Massa de raízes não comerciais: Efetuou-se a pesagem de todas as raízes de aspecto não comercial (raízes pequenas com a cor da polpa pouco atrativa) por plantas da área útil, utilizando uma balança digital manual.

f) Massa fresca da parte aérea: Foi estabelecida a partir da pesagem da parte estrutural da planta, incluindo folhas, caule, pecíolo e cepas. A massa foi determinada com auxílio de uma balança digital manual.

g) Número de raízes comercias: A partir de uma análise subjetiva, efetuou-se a contagem de todas as raízes com padrão comercial (raízes tuberosas) da área útil no momento da colheita.

h) Número de raízes não comerciais: Obtido a partir da contagem de todas as raízes de aspecto não comercial (raízes pequenas) da área útil no momento da colheita.

i) Comprimento de raízes: Obtido por mensuração das amostras de raízes pequenas, médias e grandes, pertencentes a cada clones, utilizando uma fita métrica graduada em centímetros para obtenção da média geral.

j) Diâmetro de raízes: Efetuou-se a mensuração da terço médio das raízes pequenas, médias e grandes de cada tratamento (clones) para obtenção da média geral de DR, para isso utilizou-se um paquímetro digital graduado em milímetros.

k) Tempo de cozimento: A determinação do TC foi de acordo com DOS ANJOS et al. (2014), onde fragmentos de raízes com aproximadamente 100 gramas foram imersos em água no ponto de ebulição $\left(100^{\circ} \mathrm{C}\right)$, em um recipiente com capacidade para 2L. As raízes foram consideradas cozidas quando os pedaços apresentaram pouca ou nenhuma resistência à penetração do garfo, sendo classificadas em: cozimento ótimo - 0 a 10 minutos; cozimento bom - de 11 a 20 minutos; cozimento regular - de 21 a 30 minutos e cozimento ruim - superior a 30 minutos.

1) Índice de colheita: Obtido a partir da relação entre o peso das raízes $(\mathrm{kg})$ e o peso total da planta $(\mathrm{kg})$, através da fórmula: (IC): massa da raiz / (massa da raiz + massa fresca da parte aérea) x 100. Resultado final obtido em porcentagem.

\subsection{Adubação e manejo}

A adubação foi realizada de acordo as necessidades da cultura da mandioca para o estado do Pará, segundo resultados da análise físico-química nas camadas de $0-20 \mathrm{~cm}$ do solo (Tabela 1). Portanto, foram aplicados na adubação de plantio 0,1 t ha- ${ }^{1}$ do adubo formulado 10-28-20 (N-P $\mathrm{O}_{5}{ }^{-}-$ $\mathrm{K}_{2} \mathrm{O}$ ) representando $100 \mathrm{~g} /$ cova. Não foram efetuadas aplicações químicas para o controle de pragas e/ou doenças, devido à baixa incidência destas. Para o controle de plantas daninhas, efetuou-se duas capinas mecânicas nos estádios inicias da planta e uma capina química aos dez meses após plantio.

\subsection{Análise estatística}

Os dados foram submetidos a teste de normalidade aplicando-se o teste de Shapiro-wilk, indicando distribuição normal $(\mathrm{p}>0,05)$. A análise de variância apresentou diferença significativa pelo teste $\mathrm{F}(\mathrm{p}<0,05)$ em seis variáveis das doze características avaliadas. Para o comparativo entre as médias dos tratamentos, utilizou-se o teste de Tukey a 5\% de probabilidade com uso do programa estatístico GENES (CRUZ, 2016).

Tabela 1. Propriedades físico-químicas da análise do solo da área experimental. Comunidade São José/Santarém-PA, 2018. Table 1. Physical-chemical properties of soil analysis in the experimental area. Community São José/ Santarém-PA, 2018.

\begin{tabular}{ccccccccccccc}
\hline $\mathrm{pH}$ & $\mathrm{MO}$ & $\mathrm{P}$ & $\mathrm{H}+\mathrm{Al}$ & $\mathrm{K}$ & $\begin{array}{c}\mathrm{Ca}^{2} \\
\mathrm{CaC}_{12}\end{array}$ & $\begin{array}{c}\mathrm{Mg}^{2} \\
\mathrm{~g} \mathrm{~kg})\end{array}$ & $\mathrm{CTC}$ & $\mathrm{m}$ & $\mathrm{V}$ & AREIA & SILTE & ARGILA \\
\hline 5,5 & 58 & 170 & 3,8 & 0,164 & 11 & 1,9 & 16,86 & 0 & 77 & 200 & 300 & 500 \\
\hline
\end{tabular}

${ }^{1} \mathrm{pH}=$ potencial de hidrogênio; $\mathrm{H}+\mathrm{Al}=$ acidez potencial; $\mathrm{CTC}=$ capacidade de troca catiônica; $\mathrm{m} \%=$ saturação por $\mathrm{Al}$ da $\mathrm{CTC}$ efetiva; $\mathrm{V}=$ saturação por bases da CTC a pH 7,0. Fonte: Laboratório Terra análises para agropecuária LTDA. 


\section{RESULTADOS}

A variabilidade genética existente entre os diferentes clones testados decorreu em função de que, os materiais avaliados (clones de macaxeira), são oriundos de um programa de melhoramento, onde foram utilizados diversos parentais no processo de hibridação, e consequentemente o processo de clonagem replicou os que apresentavam boas características agronômicas.

De acordo com resultados apresentados na Tabela 2, não houve diferença significativa nas características altura $(\mathrm{H})$ e diâmetro (D) de plantas, a média do caráter $\mathrm{H}$ foi de 2,62m, mas dentre os clones testados, o clone C12 apresentou maior média $3,03 \mathrm{~m}$. Na característica diâmetro do caule, a média dos clones testados foi igual a $31,90 \mathrm{~mm}$ (Tabela 2), onde clone C3 é evidenciado, pois apresentou maior média $36,36 \mathrm{~mm}$. Em relação a produtividade, ocorreu diferença estatisticamente significativa entre os diversos clones, tendo o material C5 o maior rendimento de raízes $\left(44,70 \mathrm{t} \mathrm{ha}^{-1}\right)$, diferentemente aos materiais $\mathrm{C} 1, \mathrm{C} 4$ e C11, que apresentaram os menores rendimentos de produtividade de raízes, ficando abaixo de $20 \mathrm{tha}^{-1}$ e abaixo da média experimental que foi de 26,99 t ha $^{-1}$ (Tabela 2).

A massa de raízes comerciais (MRC), apresentou diferenças entre os clones de macaxeira, o C5 se destacou, pois obteve maior média $38,73 \mathrm{t} \mathrm{ha}^{-1}$, por sua vez, o clone $\mathrm{C} 4$ apresentou menor rendimento, cerca de $9,43 \mathrm{t} \mathrm{ha}^{-1}$, e a média geral dos tratamentos foi de 20,23 $\mathrm{tha}^{-1}$. A diferença entre o clone mais produtivo e menos produtivo foi bastante expressivo (29,30 $\left.\mathrm{t} \mathrm{ha}^{-1}\right)$, indicando a ampla variabilidade existente entre os materiais estudados (Tabela 2).

$\mathrm{Na}$ variável massa de raiz não comercial (MRNC), os resultados acusaram semelhança entre os tratamentos cuja média foi equivalente a $6,86 \mathrm{t} \mathrm{ha}^{-1}$. Para a massa fresca da parte aérea (MFPA), detectou-se diferenças significativas entre os tratamentos com produtividade acima de 5 toneladas pelos clones C5 e C13. Vale salientar que o clone C5 também apresentou a maior produtividade de raízes, evidenciando seu potencial produtivo. O valor médio da MFPA foi de 3,27 kg planta $^{-1}$ (Tabela 2).

Tabela 2. Médias referentes a seis características fenotípicas avaliadas em treze novos clones de macaxeira. Altura de plantas (H), diâmetro do caule (D), produtividade (P), massa da raiz comercial (MRC), massa da raiz não comercial (MRNC) e massa fresca da parte aérea (MFPA). Table 2. Means referring to six phenotypic characteristics evaluated in thirteen new cassava clones. Plant height (H), stem diameter (D), productivity (P), commercial root mass (MRC), non-commercial root mass (MRNC) and fresh shoot weight (MFPA).

\begin{tabular}{ccccccc}
\hline CLONES & $\begin{array}{c}\mathrm{H} \\
\mathrm{m}\end{array}$ & $\begin{array}{c}\mathrm{D} \\
\mathrm{mm}\end{array}$ & $\begin{array}{c}\mathrm{P} \\
\mathrm{t} \mathrm{ha}{ }^{-1}\end{array}$ & $\begin{array}{c}\text { MRC } \\
------\mathrm{tha}^{-1}------\end{array}$ & $\begin{array}{c}\text { MFPA } \\
\mathrm{kg} \mathrm{planta}^{-1}\end{array}$ \\
\hline C1 & $2,18 \mathrm{a}$ & $26,45 \mathrm{a}$ & $16,66 \mathrm{~b}$ & $13,26 \mathrm{bc}$ & $3,40 \mathrm{a}$ & $1,73 \mathrm{~b}$ \\
C2 & $2,70 \mathrm{a}$ & $32,39 \mathrm{a}$ & $32,15 \mathrm{ab}$ & $22,73 \mathrm{abc}$ & $9,40 \mathrm{a}$ & $4,17 \mathrm{ab}$ \\
C3 & $2,66 \mathrm{a}$ & $36,36 \mathrm{a}$ & $28,60 \mathrm{ab}$ & $20,63 \mathrm{bc}$ & $7,96 \mathrm{a}$ & $3,70 \mathrm{ab}$ \\
C4 & $2,47 \mathrm{a}$ & $26,23 \mathrm{a}$ & $17,10 \mathrm{~b}$ & $9,43 \mathrm{c}$ & $6,16 \mathrm{a}$ & $2,52 \mathrm{ab}$ \\
C5 & $2,84 \mathrm{a}$ & $33,67 \mathrm{a}$ & $44,70 \mathrm{a}$ & $38,73 \mathrm{a}$ & $5,96 \mathrm{a}$ & $5,13 \mathrm{a}$ \\
C6 & $2,50 \mathrm{a}$ & $31,41 \mathrm{a}$ & $33,36 \mathrm{ab}$ & $26,83 \mathrm{ab}$ & $6,53 \mathrm{a}$ & $2,71 \mathrm{ab}$ \\
C7 & $2,67 \mathrm{a}$ & $29,92 \mathrm{a}$ & $26,90 \mathrm{~b}$ & $20,80 \mathrm{bc}$ & $6,10 \mathrm{a}$ & $2,01 \mathrm{~b}$ \\
C8 & $2,46 \mathrm{a}$ & $30,66 \mathrm{a}$ & $31,30 \mathrm{ab}$ & $24,10 \mathrm{abc}$ & $7,20 \mathrm{a}$ & $3,00 \mathrm{ab}$ \\
C9 & $2,47 \mathrm{a}$ & $35,00 \mathrm{a}$ & $21,30 \mathrm{~b}$ & $14,93 \mathrm{bc}$ & $9,10 \mathrm{a}$ & $3,24 \mathrm{ab}$ \\
C10 & $2,83 \mathrm{a}$ & $29,00 \mathrm{a}$ & $24,18 \mathrm{~b}$ & $17,50 \mathrm{bc}$ & $6,68 \mathrm{a}$ & $2,47 \mathrm{ab}$ \\
C11 & $2,58 \mathrm{a}$ & $28,66 \mathrm{a}$ & $18,25 \mathrm{~b}$ & $13,30 \mathrm{bc}$ & $4,95 \mathrm{a}$ & $2,40 \mathrm{ab}$ \\
C12 & $3,03 \mathrm{a}$ & $31,00 \mathrm{a}$ & $32,30 \mathrm{ab}$ & $24,15 \mathrm{abc}$ & $8,30 \mathrm{a}$ & $4,39 \mathrm{ab}$ \\
C13 & $2,73 \mathrm{a}$ & $34,00 \mathrm{a}$ & $24,10 \mathrm{~b}$ & $16,65 \mathrm{bc}$ & $7,50 \mathrm{a}$ & $5,08 \mathrm{a}$ \\
\hline Média & 2,62 & 31,9 & 26,99 & 20,23 & 6,86 & 3,27 \\
\hline QM & 0,13 & 24,7 & $189,60^{*}$ & $171,10 *$ & 8,22 & $3,82^{*}$ \\
\hline CV $(\%)$ & 14,05 & 12,02 & 20,78 & 28,57 & 39,28 & 30,41 \\
\hline
\end{tabular}

*Médias seguidas por letras distintas nas colunas diferem estatisticamente entre si, pelo teste de Tukey $(\mathrm{p}<0,05)$.

O número médio de raízes comerciais por planta (NRC) é um importante fator na produção de mandioca de mesa por influenciar diretamente nesse caráter. Dentre os clones avaliados não houve diferença significativa, cuja média foi de 3,43 raízes por planta, entretanto, o clone C9 destacou-se, pois obteve rendimento de 5,60 raízes por planta, mas esta vantagem não influenciou significativamente na produção total de raízes (Tabela 3).

O número de raízes não comerciais (NRNC) é uma caraterística indesejável por não poder ser comercializado, diminuindo a produtividade de raízes comerciais. Todos os tratamentos apresentaram NRNC estatisticamente semelhantes cuja média foi de 2,87 raízes por planta, tendo o tratamento C11 o maior NRNC por planta, média de 4,44 raízes, influenciando negativamente na produtividade de raízes deste clone (Tabelas 2 e 3 ).

Para o comprimento médio das raízes, embora seja um fator de extrema importância na produtividade, os tratamentos avaliados apresentaram comportamento semelhante, com média geral dos clones testados equivalente a 23,16 cm, o clone C9 destacou-se com maior média $29,53 \mathrm{~cm}$ (Tabela 3).

Em relação ao diâmetro médio da raiz não ocorreu distinção entre as médias dos tratamentos, entretanto o clone C12 destacou-se com $79,85 \mathrm{~mm}$, adverso ao C9 que apresentou menor média $56,24 \mathrm{~mm}$, a média dos clones testados foi de $65,92 \mathrm{~mm}$ (Tabela 3).

A característica tempo médio de cozimento das raízes (TC), apresentou diferença significativa entre os diferentes materiais avaliados. Dentre os aos treze clones de macaxeira testados, 12 obtiveram tempo médio de cozimento inferior a trinta minutos, com destaque para o clone C11, que obteve média de 12,30 minutos, sendo este classificado como tempo de cozimento bom, diferentemente do tratamento C13, que foi o único material a apresentar tempo médio superior de 30 minutos, sendo classificado com tempo de cozimento ruim. 
A média geral dos tratamentos para o TC foi de 21,04 minutos.

O caráter índice de colheita (IC) dos clones de macaxeira foi estatisticamente significativo $(p<0,05)$, obtendo variação de $32,67 \%$ a $57,94 \%$ para os clones C13 e C7 respectivamente, os dados indicam um variação moderada entre os clones testados, sendo assim, os dados obtidos possibilitaram a seleção dos materiais com maiores rendimentos de IC, tendo os clones $\mathrm{C} 1, \mathrm{C} 6, \mathrm{C} 7$ e $\mathrm{C} 8$ apresentado as médias superiores a $50 \%$, que é o desejável pelos programas de melhoramento genético da cultura da mandioca, diferentemente do clone $\mathrm{C} 13$ que obteve o menor rendimento, apenas $32,67 \%$ de IC. A média dos tratamentos foi de 46,64\%, valor este inferior à média aceitável (Tabela 3).

Tabela 3. Médias referentes ao número médio de raízes comerciais (NRC), número médio de raízes não comerciais (NRNC), comprimento de raiz (CR), diâmetro de raiz (DR), tempo de cozimento (TC) e índice de colheita (IC).

Table 3. Averages referring to the average number of commercial roots (NRC), average number of non-commercial roots (NRNC), root length (CR), root diameter (DR), cooking time (TC) and harvest index (IC).

\begin{tabular}{|c|c|c|c|c|c|c|}
\hline \multirow{2}{*}{ CLONES } & NRC & NRNC & \multirow{2}{*}{$\begin{array}{l}\mathrm{CR} \\
\mathrm{cm}\end{array}$} & \multirow{2}{*}{$\begin{array}{l}\text { DR } \\
\mathrm{mm}\end{array}$} & \multirow{2}{*}{$\begin{array}{c}\text { TC } \\
\text { min. }\end{array}$} & \multirow{2}{*}{$\begin{array}{l}\mathrm{IC} \\
\%\end{array}$} \\
\hline & \multicolumn{2}{|c|}{---------n. ${ }^{\circ}---------$} & & & & \\
\hline C1 & $2,10 \mathrm{a}$ & $0,99 a$ & $23,78 a$ & $59,94 a$ & $14,97 \mathrm{~cd}$ & $54,22 \mathrm{ab}$ \\
\hline $\mathrm{C} 2$ & $2,49 a$ & $3,44 a$ & $20,39 a$ & $60,13 \mathrm{a}$ & $21,40 \mathrm{bcd}$ & $44,39 \mathrm{ab}$ \\
\hline C3 & $2,33 a$ & $2,99 \mathrm{a}$ & $24,55 \mathrm{a}$ & $58,07 \mathrm{a}$ & $22,11 \mathrm{bcd}$ & $45,43 \mathrm{ab}$ \\
\hline $\mathrm{C} 4$ & $1,55 \mathrm{a}$ & $3,33 a$ & $22,66 a$ & $60,89 a$ & $20,25 \mathrm{bcd}$ & $39,88 \mathrm{ab}$ \\
\hline C5 & $3,88 \mathrm{a}$ & $2,22 \mathrm{a}$ & $27,05 a$ & $76,00 \mathrm{a}$ & $21,26 \mathrm{bcd}$ & $47,46 \mathrm{ab}$ \\
\hline C6 & $3,00 \mathrm{a}$ & $2,44 a$ & $22,67 a$ & $69,80 \mathrm{a}$ & $23,30 \mathrm{bc}$ & $55,58 \mathrm{a}$ \\
\hline $\mathrm{C} 7$ & $2,83 a$ & $2,66 a$ & $22,32 \mathrm{a}$ & $65,81 \mathrm{a}$ & $17,60 \mathrm{bcd}$ & $57,94 \mathrm{a}$ \\
\hline C8 & $3,32 \mathrm{a}$ & $3,16 \mathrm{a}$ & $20,66 a$ & $71,33 \mathrm{a}$ & $24,74 \mathrm{abc}$ & $51,01 \mathrm{ab}$ \\
\hline C9 & $5,60 \mathrm{a}$ & $2,16 \mathrm{a}$ & $29,53 a$ & $56,24 \mathrm{a}$ & $16,91 \mathrm{bcd}$ & $42,13 \mathrm{ab}$ \\
\hline C10 & $4,36 a$ & $3,51 \mathrm{a}$ & $20,99 a$ & $65,55 a$ & $16,72 \mathrm{bcd}$ & $49,43 \mathrm{ab}$ \\
\hline C11 & $3,98 \mathrm{a}$ & $4,44 a$ & $21,06 a$ & $59,96 a$ & $12,30 \mathrm{~d}$ & $43,75 \mathrm{ab}$ \\
\hline C12 & $4,33 a$ & $2,35 a$ & $20,39 a$ & $79,85 \mathrm{a}$ & $26,79 \mathrm{ab}$ & $42,45 \mathrm{ab}$ \\
\hline C13 & $4,88 \mathrm{a}$ & $2,60 \mathrm{a}$ & $20,44 a$ & $73,47 a$ & $35,22 \mathrm{a}$ & $32,67 b$ \\
\hline Média & 3,43 & 2,87 & 23,16 & 65,92 & 21,04 & 46,64 \\
\hline QM & 4,24 & 2,02 & 23,27 & $170,50^{*}$ & $103,90 *$ & $146,00^{*}$ \\
\hline $\mathrm{CV}(\%)$ & 51 & 46,65 & 21,78 & 13,22 & 17,16 & 16,38 \\
\hline
\end{tabular}

*Médias seguidas por letras distintas nas colunas diferem estatisticamente entre si, pelo teste de Tukey $(\mathrm{p}<0,05)$.

Os resultados apresentados na Tabela 4, denotam correlação significativa da variável altura de plantas com a produtividade $(r=0,54)$, massa fresca da parte aérea $(r=0,60)$ e diâmetro médio das raízes $(\mathrm{r}=0,58)$.

Em relação a variável diâmetro do caule (D), esta apresentou correlação significativa entre as características massa da raiz não comercial $(r=0,58)$ e massa fresca da parte aérea $(\mathrm{r}=0,54)$, ambas com correlação positiva e de moderada magnitude, já com o índice de colheita $(r=-0,60)$, o caráter diâmetro médio do caule (D) apresentou correlação significativa, porém negativa e de moderada magnitude (Tabela 4).

Tabela 4. Resumo da análise de correlação fenotípica entre doze características agronômicas avaliadas em treze novos clones de macaxeira nas condições edafoclimáticas do município de Santarém-PA.

Table 4. Summary of the phenotypic correlation analysis between twelve agronomic traits evaluated in thirteen new cassava clones in the edaphoclimatic conditions of the municipality of Santarém-PA.

\begin{tabular}{|c|c|c|c|c|c|c|c|c|c|c|c|c|}
\hline Variável & $\mathrm{H}$ & $\mathrm{D}$ & $\mathrm{P}$ & MRC & MRNC & MFPA & NRC & NRNC & $\mathrm{CR}$ & DR & $\mathrm{TC}$ & $\mathrm{IC}$ \\
\hline$\overline{\mathrm{H}}$ & 1,00 & & & & & & & & & & & \\
\hline $\mathrm{D}$ & 0,17 & 1,00 & & & & & & & & & & \\
\hline $\mathrm{P}$ & $0,54 *$ & 0,18 & 1,00 & & & & & & & & & \\
\hline MRC & 0,46 & 0,07 & $0,98^{*}$ & 1,00 & & & & & & & & \\
\hline MRNC & 0,45 & $0,58^{*}$ & 0,32 & 0,17 & 1,00 & & & & & & & \\
\hline MFPA & $0,60 *$ & $0,54^{*}$ & $0,61 *$ & $0,53^{*}$ & $0,58^{*}$ & 1,00 & & & & & & \\
\hline NRC & 0,39 & 0,01 & 0,09 & 0,11 & 0,35 & 0,42 & 1,00 & & & & & \\
\hline NRNC & 0,20 & 0,20 & $-0,17$ & $-0,26$ & 0,32 & $-0,04$ & 0,18 & 1,00 & & & & \\
\hline CR & $-0,02$ & 0,36 & 0,17 & 0,22 & 0,15 & 0,23 & 0,30 & $-0,31$ & 1,00 & & & \\
\hline DR & $0,58^{*}$ & $-0,08$ & $0,63^{*}$ & $0,63^{*}$ & 0,04 & 0,51 & 0,30 & $-0,31$ & $-0,06$ & 1,00 & & \\
\hline TC & 0,37 & 0,41 & 0,37 & 0,28 & 0,44 & $0,69 *$ & 0,19 & $-0,21$ & $-0,18$ & $0,64^{*}$ & 1,00 & \\
\hline IC & $-0,14$ & $-0,60 *$ & 0,24 & 0,32 & $-0,52$ & $-0,53^{*}$ & $-0,53^{*}$ & $-0,31$ & $-0,30$ & 0,12 & $-0,31$ & 1,00 \\
\hline
\end{tabular}

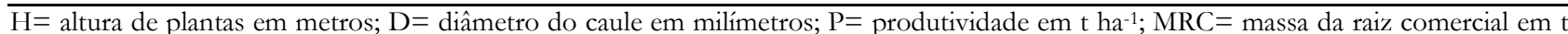
$\mathrm{ha}^{-1}$; MRNC $=$ massa da raiz não comercial em $\mathrm{t} \mathrm{ha}^{-1} ; \mathrm{MFPA}=$ massa fresca da parte aérea, em $\mathrm{kg}$ planta ${ }^{1}$; NRC $=$ número médio de raízes comerciais por planta; $\mathrm{NRNC}=$ número médio de raízes não comercias por planta; $\mathrm{CR}=$ comprimento de raiz em centímetros; $\mathrm{DR}=$ diâmetro de raiz em milímetro; $\mathrm{TC}=$ tempo de cozimento em minutos e IC= índice de colheita em \% . * Significativo a 5\% de probabilidade pelo teste t.

A produtividade apresentou associação de forma significativa e positiva com a massa da raiz comercial $(\mathrm{r}=$
$0,98)$, massa fresca da parte aérea $(r=0,61)$ e diâmetro médio das raízes $(\mathrm{r}=0,63)$, porém, apenas a característica massa $\mathrm{da}$ 
raiz comercial obteve correlação de elevada magnitude, os outros dois caracteres (MFPA e DR) ambos apresentaram correlação de moderada à elevada magnitude. Por sua vez, o caráter massa da raiz comercial, correlacionou-se de forma significativa e positiva, porém de moderada magnitude com a variável massa fresca da parte aérea $(\mathrm{r}=0,53)$ e diâmetro médio das raízes $(r=0,63)$.

Os resultados apontaram em relação a caraterística do diâmetro médio das raízes (DR), uma correlação significativa e positiva, de moderada à elevada magnitude com a variável tempo de cozimento $(r=0,64)$, sendo assim, os dados são indicativos de que materiais que dispõe de menores médias de DR, consequentemente tendem a apresentar menores médias em relação a variável tempo médio de cozimento das raízes.

\section{DISCUSSÃO}

A variabilidade dentre os diferentes genótipos avaliados decorreu em função de que, os materiais em estudo, são oriundos de um programa de melhoramento cujo a origem destes procedeu-se a partir do intercruzamento entre diferentes variedades amplamente adotadas nas comunidades próximas a cidade de Santarém, especificamente na comunidade do tabocal no baixo Amazonas. De acordo com Ebertz \& Palomino (2017) a ampla variabilidade na cultura da mandioca pode ser explicada pelo fato de a espécie ser alógama, ou seja, a polinização cruzada que permite a geração natural de novas combinações, as quais são inicialmente propagadas via semente, e posteriormente propagadas de forma assexuada ou vegetativa. Os mesmos procedimentos de hibridação, e consequentemente a clonagem dos genótipos superiores, foram adotados no programa de melhoramento que resultou nos clones avaliados na presente pesquisa.

Prates et al. (2017), avaliando 14 genótipos de mandioca obteve resultados adversos em relação a variável altura de plantas, a média foi de $1,72 \mathrm{~m}$, valor este inferior à média obtida no presente estudo que foi equivalente a $2,62 \mathrm{~m}$ de altura de plantas. Para Prates et al. (2017), plantas de porte médio e alto facilitam as práticas de manejo, entretanto são propicias ao acamamento, ou seja, ventos fortes ocasionam a quebra das hastes, dificultando o processo de colheita. Em relação a característica diâmetro médio do caule, houve uma variação de 26,23mm (clone C4) a 36,36mm (tratamento C3), resultados diferentemente encontrados por Costa (2018), em estudo com a cultura da mandioca, no mesmo período de colheita (12 meses), obteve variação de 17,7 a 21,2 mm de diâmetro de caule, e afirma que o diâmetro das plantas de mandioca está diretamente associado ao período de colheita, quanto maior idade de colheita, maior variação no diâmetro médio das plantas.

A produtividade é a principal característica de interesse econômico na cultura da mandioca, e nessa variável, todos os clones testados obtivam média superior à média nacional e estadual, que varia de 10 a $15 \mathrm{t} \mathrm{ha}^{-1}$ (MODESTO JUNIOR; ALVES, 2016). Vieira et al. (2015) em estudo semelhante desenvolvido em área experimental localizada no município de Unaí, Minas Gerais, apresentou produtividade superior a $30 \mathrm{t} \mathrm{ha}^{-1}$ em 8 acessos de mandioca de mesa, resultado este que denotou supremacia em relação a produtividade na região do Cerrado, que é de $13 \mathrm{t} \mathrm{ha}^{-1}$.

Tironi et al. (2015) em estudo sobre o desempenho de cinco cultivares de mandioca em diferentes anos agrícolas, obteve rendimentos de 20,40 $\mathrm{t} \mathrm{ha}^{-1}$ a $32,80 \mathrm{t} \mathrm{ha}^{-1}$ de produtividade de raízes comerciais no primeiro ano agrícola, valor este similar ao encontrado no presente estudo, que apresentou valores de 9,43 a 38,73 tha $\mathrm{t}^{-1}$ no caráter massa da raiz comercial, e 3,40 a 9,40 t ha ${ }^{-1}$ na variável massa da raiz não comercial.

Nick et al. (2010) avaliando a divergência genética entre subamostras de mandioca, obteve rendimento médio de 9,15 t ha ${ }^{-1}$ de biomassa da parte aérea. No presente estudo houve uma variação da MFPA de 1,73 a $5,13 \mathrm{~kg}_{\text {planta }}{ }^{-1}$, o que equivale a $17,30 \mathrm{t} \mathrm{ha}^{-1}$ a $51,30 \mathrm{t} \mathrm{ha}^{-1}$, a média dos tratamentos corresponde a $32,70 \mathrm{t} \mathrm{ha}^{-1}$, sendo superior aos valores encontrados pelo autor. Fukuda et al. (2002) salienta a importância MFPA quando o objetivo é a seleção indireta para o rendimento de raízes com base nesta característica. Esta afirmação foi confirmada no presente trabalho esclarecida pela correlação positiva e significativa $(r=0,61)$ entre a P e MFPA. Dentre as características número de raízes comerciais e não comercias, não houve distinção entre as médias dos clones testados, os resultados corroboram ao encontrado por Jesus et al. (2013), na qual não obteve diferença significativa entre dez genótipos de mandioca, entretanto o número médio de raízes comerciais foi de 6,7 raízes por planta, dado este superior aos valores encontrados neste estudo que obteve média de 3,43 raízes comerciais por planta.

Em estudo realizado por Junior (2019) ao avaliar mandiocas sob diferentes sistemas de manejo do solo, foi observado que o melhor tratamento com uso de adubação química apresentou $27,60 \mathrm{~cm}$ de comprimento de raiz e 25,40 $\mathrm{mm}$ de diâmetro de raiz, apresentando assim, valores próximos com o presente estudo para o comprimento de raiz com 23,16 cm, com exceção para o diâmetro médio de raiz que foi superior com $65,92 \mathrm{~mm}$.

Em relação ao tempo de cozimento das raízes, dos treze clones avaliados, doze apresentaram tempo médio de cozimento inferior a 30 minutos. Os resultados são similares ao encontrado por Teixeira (2017), que caracterizou dezenove variedades de mandioca de mesa e obteve tempo médio de cozimento na faixa de 10 a 31 minutos. O tempo médio de cozimento da raiz é uma característica culinária desejável pelos programas de melhoramento de mandioca de mesa, e de acordo com Dos Anjos et al. (2014), o tempo médio de cozimento superior a 30 minutos é classificado com ruim, além de ser um indicativo de raízes de baixa qualidade, quanto menor o tempo de cocção, maior a qualidade de massa gerada pelas raízes de mandioca de mesa.

O índice de colheita (IC) é a razão dada entre o peso das raízes e o peso total da planta. Os valores obtidos em relação a variável IC corroboram aos resultados observados por Lessa et al. (2017) que apresentaram variação de 38,3 a $55,83 \%$. De acordo Peixoto et al. (2005), o índice de colheita é considerado satisfatório quando acima de $50 \%$, no presente estudo, tal índice foi obtido em quatro materiais entre os treze clones testados. Segundo Avijala (2013), o índice de colheita é a característica que revela a distribuição da matéria seca para partes economicamente úteis da planta, sendo as raízes os órgãos de maior interesse no cultivo de mandioca, o índice de colheita consegue fornecer um bom balanço entre a produção total de carboidratos pelas plantas e sua distribuição para o sistema radicular.

O coeficiente de correlação ( $\mathrm{r}$ ) visa medir o grau de associação linear entre duas variáveis quantitativas, os índices adimensionais possuem valores entre -1 e 1 , que indica a 
relação linear entre dois conjuntos de dados, sendo assim, os resultados no presente estudo revelaram pela análise de correlação simples uma tendência de que genótipos com elevada estatura podem apresentar maior massa de parte aérea, e consequentemente maior produtividade, um vez que os dados obtidos apresentaram um associação de moderada magnitude da variável altura da planta $(\mathrm{H})$ com o diâmetro médio das raízes (DR), assim como a característica produtividade é influenciada pelo massa fresca da raiz, quanto maior o DR, maior a massa da raiz comercial (MRC). Segundo Vieira et al. (2014), isso pode ser explicado pelo fato de que os genótipos com maiores rendimento de massa fresca da parte aérea são mais competitivos em razão de possuírem maior número de hastes e folhas e, por consequência, produzirem mais fotoassimilados para serem armazenados nas raízes de reserva e se destacarem mais nas primeiras gerações de seleção.

O caráter índice de colheita mostrou correlacionar-se de forma significativa, porém negativa e de moderada magnitude, com o diâmetro do caule e massa fresca da parte aérea, resultados análogos aos obtidos por Vieira et al. (2014), o que se justifica pela forma do cálculo do índice de colheita. A produtividade apresentou associação elevada com a massa da raiz comercial, uma vez que a produtividade é obtida pela massa das raízes como também verificado por Tironi et al. (2015). O caráter produtividade também se correlacionou significativamente com o diâmetro de raiz, resultados similares obtidos por Prates et al. (2017), que apresentou associação de moderada à elevada magnitude $(\mathrm{r}=0,70)$, indicando que maiores médias de diâmetro de raiz resultam em raízes mais pesadas. À semelhança dos resultados apresentados por Prates et al. (2017), o comprimento e o diâmetro de raízes não apresentaram correlação significativa entre si, indicando que o crescimento de ambas as características fenotípicas ocorre de forma independente.

O tempo de cozimento é um caráter de extrema importância no melhoramento genético da mandioca de mesa, no presente estudo, o mesmo obteve associação de moderada magnitude com a massa fresca da parte aérea e diâmetro médio das raízes. Vieira et al. (2014) na mesma linha de estudo obteve correlação significativa entre o tempo de cocção e teor de amido nas raízes. Em estudos realizados na cultura da cenoura por Greeve et al. (1994), citado por Dos Anjos et al. (2014), foi observado que, devido ao amido possuir caráter higroscópico, seu acúmulo nas raízes favorece o influxo de água nas células, o que diminui a resistência da parede celular e provoca uma hidratação que reduz a força de adesão entre as células e o amaciamento dos tecidos, e consequente favorece uma redução no tempo de cozimento.

Vieira et al. (2014) também obteve associação significativa e positiva entre a massa da parte aérea e o teor de amido nas raízes, muito embora tenha sido de baixa magnitude, este é um indicativo de que os clones com maior massa de parte aérea, podem apresentar maiores médias de diâmetro de raiz, e tendem a acumular maior quantidade de amido nas raízes, sendo assim, essas correlações apresentam indícios da possibilidade de seleção de clones de mandioca de mesa com baixos tempos para o cozimento de forma precoce nas primeiras gerações de propagação assexuada, o que significa ganho de tempo para programas de melhoramento.

\section{CONCLUSÕES}

Os clones avaliados nas condições edafoclimáticas do município de Santarém, Oeste do Pará, apresentam bom desempenho nos caracteres altura e diâmetro das plantas, produtividade, diâmetro médio das raízes, massa fresca da parte aérea e tempo de cozimento das raízes.

A produtividade média dos clones testados foi superior à média regional e nacional, indicando potencial dos genótipos.

Os clones C5, C6, C12, C2 e C8 obtiveram os maiores rendimento de produtividade.

O caráter produtividade está correlacionado positivamente com a característica massa fresca da parte aérea, massa da raiz comercial e diâmetro da raiz.

\section{AGRADECIMENTOS}

À Universidade Federal do Oeste do Pará - UFOPA pela concessão de auxílio financeiro para desenvolvimento do projeto.

Aos produtores rurais da comunidade São José do município de Santarém-PA pela concessão de área para execução do experimento.

\section{REFERÊNCIAS}

AVIJALA, M. F. Diversidade e estimativas de parâmetros genéticos em mandioca (Manihot esculenta crantz), oriunda de Moçambique. 2013. 91f. Dissertação (Mestrado em Genética e Melhoramento) - Universidade Federal de Viçosa, Viçosa, 2013.

BOREM, A. Melhoramento de Plantas. Viçosa: Editora UFV, 2005. 525p.

CEBALLOS, H.; IGLESIAS, C. A.; PÉREZ, J. C.; DIXON, A. G. O. Cassava breeding: opportunities and challenges. Plant Molecular Biology, v. 56, p. 503-516, 2004.

CONAB_Companhia Nacional de Abastecimento. Mandioca: raiz, farinha e fécula. Conjuntura mensal, Abril, 2019. Disponível em: https://www.conab.gov.br/info-agro/analises-domercado-agropecuario-e extrativista/analises-domercado/historico-mensal-de-mandioca/item/11655mandioca-analise-mensal-abril-2019. Acesso em: 26 ago 2019.

COSTA, R. M. Produtividade da mandioca em resposta ao espaçamento e adubação de cobertura potássica no Brejo Paraibano. 2018. 33f. Dissertação (Mestrado em Agronomia) - Universidade Federal da Paraíba, Areia, 2018.

CRUZ, C. D. Programa Genes V.2014.6.1 - Aplicativo computacional em genética e estatística. Disponível em: http://www.ufv.br/dbg/genes/genes,htm[con. Acesso em : ago set 2019.

DOS ANJOS, D. N.; VIANA, A. E. S.; CARDOSO, A. D.; MATSUMOTO, S. N. Características culinárias e teor de amido de variedades de mandioca avaliadas em dois períodos na região Sudeste da Bahia. Enciclopédia Biosfera, Goiânia, v. 10, n. 18, p. 785-793, 2014.

EBERTZ, O.; PALOMINO, E. C. Caracterização morfológica de genótipos de Manihot esculenta crantz. obtidos por sementes. Agroecossistemas, Belém, v. 9, n. 2, p. 66-77, 2017.

EMBRAPA. Centro Nacional de Pesquisa de Mandioca e Fruticultura. Disponível em: http://www.cnpmf.embrapa.br/. Acesso em: 10 mar 2019.

FAO. Dados da produção mundial da mandioca. Disponível 
em: <http://faostat.fao.org/ site/339/default.aspx>. Acesso em: 20 abr 2019.

FUKUDA, W. M. G.; SILVA, S. O. E. Melhoramento de mandioca no Brasil. In: CEREDA, M. P. (Ed.). Agricultura: Tuberosas amilaceas latino americanas. São Paulo: Fundação Cargil, 2002. p. 242-257.

GONÇALVES, G. M.; VIANA, A. P.; REIS, L. S.; NETO, F. V. B.; AMARAL JUNIOR, A. T.; REIS, L. S. Correlações fenotípicas e genético-aditivas em maracujáamarelo pelo delineamento I. Ciência e Agrotecnologia, Lavras, v. 32, n. 5, p. 1413-1418, set./out. 2008.

GREVE, L. C.; MCARDLE, R. N.; GOHLKE, J. R.; LABAVITCH, J. M. Impact of heating on carrot firmness: changes in cell-wall components. Journal of the Science of Food and Agriculture, v. 42, n. 12, p. 2900-2906, 1994. DOI: http://dx.doi.org/00218561/94/1442-2900\$04.50/0

IBGE_Instituto Brasileiro de Geografia e Estatística. Levantamento Sistemático da produção agrícola. $2019 . \quad$ Disponível em: https://sidra.ibge.gov.br/home/lspa/brasil Acesso em: 27 ago 2019.

INMET_Instituto Nacional de Meteorologia, 2018. Disponível em: <http://www.inmet.gov.br/portal/index.php?r=home/ page\&page $=$ rede_estacoes_conv_g43 raf $>$. Acesso em: 14 set 2019.

JESUS, A. M. S.; CARVALHO, S. P.; CUSTODIO, T. N.; OLIVEIRA, P. M.; GOMES, C. N. Avaliação agronômica de cultivares e clones de mandioca em área irrigada no Norte de Minas Gerais. Scientia Agraria Paranaensis, Marechal Cândido Rondon, v. 12, n. 3, p. 205-210, 2013. DOI: 10.18188/19831471/sap.v12n3p205-210

JUNIOR, L. B. B.; CARVALHO, F. L. C.; SOUSA, R. R.; ARAUJO, R. L.; BARROS, W. K. F. C.; VERAS, F. H. C.; BANDEIRA, A. C.; SILVA, R. B. Avaliação da cultura da mandioca em diferentes sistemas de manejo do solo. Global Science and Technology, Rio Verde, v. 12, n. 2, p. 152-169, 2019.

LARA, A. C. C.; BICUDO, S. J.; BRACHTVOGEL, E. L.; ABREU, M. L.; CURCELLI, F. Melhoramento genético da cultura da mandioca (Manihot esculenta cranta). Revista Raízes e Amidos Tropicais, Botucatu, v. 4, p. 54-64, 2008.

LESSA, L. S.; LEDO, C. A. S.; SANTOS, V. S. Seleção de genótipos de mandioca com índices não paramétricos. Revista Raízes e Amidos Tropicais, Botucatu, v. 13, n. 1, p. 1-17, 2017. DOI: http://dx.doi.org/10.17766/1808981X.2017v13n1p1-17

MODESTO JUNIOR, M. S.; ALVES, R. N. B.; Cultura da mandioca: Aspectos socioeconômicos, melhoramento genético, sistemas de cultivo, manejo de pragas e doenças e agroindústria. 21 ed. Brasília, DF: Embrapa, 2016. 40p.

NICK, C.; DE CARVALHO, S. P; JESUS, A. M. S.; CUSTÓDIO, T. N; MARIM, B. G.; DE ASSIS, L. H. B. Divergência genética entre subamostras de mandioca. Bragantia, Campinas, v. 69, n. 2, p. 289-298, 2010.
PEIXOTO, J. R.; BERNARDES, S. R.; SANTOS, C. M.; BONNAS, D. S.; FIALHO, J. F.; OLIVEIRA, J. A. Desempenho agronômico de variedades de mandioca mansa em Uberlândia. Revista Brasileira de Mandioca, v. 18, n. 1, p. 19-24, 2005.

PRATES, C. J. N.; GUIMARAES, D. G.; VIANA, A. E. S.; CARDOSO, A. D.; TEIXEIRA, P. R. G.; CARVALHO, K. D. Caracterização morfológica de genótipos de mandioca (Manibot esculenta crantz). Scientia Plena, Sergipe, v. 13, n. 9, p. 1-11, 2017. DOI: 10.14808/sci.plena.2017.090201

ROCHA, J. S.; COELHO FILHO, M. A.; LEDO, C. A. S.; SANTOS, V. S.; RIBEIRO, R. N. S.; JUNIOR, F. A. G. Avaliação de clones de mandioca mansa sob condições de sequeiro e irrigado. In: Congresso Brasileiro de Mandioca, 14. Anais... Cruz das Almas-BA: UFRB, 2011. 6p.

SEDAP_Secretaria de Desenvolvimento Agropecuario e da Pesca. Panorama agrícola do Pará - Mandioca. Disponível

http://www.sedap.pa.gov.br/content/mandioca. Acesso em: 02 nov 2019.

TEIXEIRA, P. R. G.; VIANA, A. E. S.; CARDOSO, A. D.; MOREIRA, G. L. P.; MATSUMOTO, S. N.; RAMOS, P. A. S. Physical-chemical characteristics of sweet cassava varieties. Revista Brasileira de Ciências Agrárias, Recife, v. 12, n. 2, p. 158-165, 2017. DOI:10.5039/agraria.v12i2a5433

TIRONI, L. F.; UHLMANN, L. O.; STRECK, N. A.; SAMBORANHA, F. K.; FREITAS, C. P. D. O. D.; SILVA, M. R. D. Desempenho de cultivares de mandioca em ambiente subtropical. Bragantia, Campinas, v. 74, n. 1, p. 58-66, 2015. DOI: http://dx.doi.org/10.1590/16784499.0352

VIEIRA, E. A.; FIALHO, F. J.; CARVALHO, L. J. C. B. (2015). Correlação fenotípica entre caracteres agronômicos em população segregante de mandioca de mesa. Revista Ceres, Viçosa, v. 61, n. 4, p. 523-529, 2014. DOI: http://dx.doi.org/10.1590/0034737X201461040011

VIEIRA, E. A.; FIALHO, F. J.; CARVALHO, L. J. C. B.; MALAQUIAS, J. V.; FERNANDES, F. D. Desempenho agronômico de acessos de mandioca de mesa em área de Cerrado no município de Unaí, região noroeste de Minas Gerais. Científica, Jaboticabal, v. 43, n. 4, p. 371-377, 2015.

DOI: http://dx.doi.org/10.15361/19845529.2015v43n4p371377

VIEIRA, E. A.; FIALHO, J. F.; FALEIRO, F. G.; BELLON, G.; FONSECA, K. G. da; SILVA, M. S.; PAULAMORAES, S. V. de; CARVALHO, L. J. C. B. Caracterização fenotípica e molecular de acessos de mandioca de indústria com potencial de adaptação às condições do Cerrado do Brasil Central. Semina Ciências Agrárias, v. 34, p. 567-582, 2013. DOI: http://dx.doi.org/10.5433/16790359.2013v34n2p567 